\title{
NBSIR 78-1480
}

\section{Evaluation of Methodology for Analysis of Halocarbons in the Upper Atmosphere: Phase I}

Ernest E. Hughes, Williarn D. Dorko, and John K. Taylor

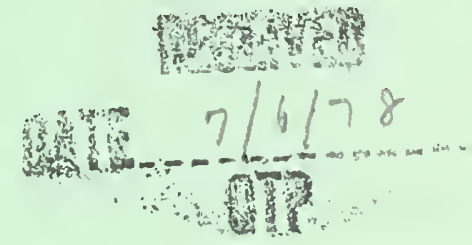

National Bureau of Standards

Department of Commerce

Washington, D.C. 20234

March 1978

Final Report: Phase I

Issued June 1978

Prepared for

National Aeronautics and Space Administration

Washington, D.C. 20546 

EVALUATION OF METHODOLOGY FOR ANALYSIS OF HALOCARBONS IN THE UPPER ATMOSPHERE: PHASE I

Ernest E. Hughes, William D. Dorko, and John K. Taylor

National Bureau of Standards

Department of Commerce

Washirıton, D.C. 20234

March 1978

Final Report: Phase I

issued June 1978

Prepared for

National Aeronautics and Space Administration

Washington, D.C. 20546

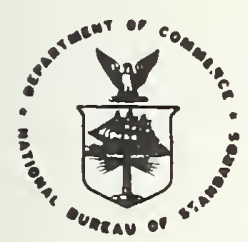

U.S. DEPARTMENT OF COMMEFPCE, Juanita M. Krops, Secretary

Dr. Sidney Harman. Under Secretary

Jordan J. Baruch, Assistant Secretary fior Science and Technology

NATIONAL BUREAU OF STANDARDS, E innest Ambler, Director 

CONTENTS

$\underline{\text { Page }}$

1. INTRODUCTION . . . . . . . . . . . . . 1

2. PREPARAtion OF SAMPles . . . . . . . . . . . 3

3. CYLINDERS AND CYLINDER PREPARATION . . . . . . . . 4

4. FILLING THE CYLINDER . . . . . . . . . . . 5

5. HOMOGENEITY VERIFICATION . . . . . . . . . . 7

5.1 Measurement Method and Standards . . . . . 7

5.2 Homogeneity Data... . . . . . . . . . 9

6. STABILITY OF SAMPLES . . . . . . . . . . . 14

7. PARTICIPATION. . . . . . . . . . . 17

8. RESUltS OF COllaborative TEST. . . . . . . . . 18

9. CONCLUSION . . . . . . . . . . . . . 25

10. ACKNOWLEDGEMENT . . . . . . . . . . 26

11. REFERENCES . . . . . . . . . . . . 27

12. APPENDIX . . . . . . . . . . . 28 
1. Analysis of Halocarbon in Each Sample, .... $\frac{\text { Page }}{10}$ Concentration in Parts per Trillion by Mole

2. Replicate Analyses of Several Samples in . . . Both A and B Series Concentration in Parts per Trillion by Mole

3. Analysis of Nitrous Oxide in Several Samples,. . Concentration in Parts per Billion by Mole

4. Analysis of Halocarbons in Samples after... . Return, Concentration in Parts per Trillion by Mole

5. Analysis of Samples for Nitrous Oxide After. . . Return. Concentration in Parts per Billion by Mole

6. Analytical Results for $\mathrm{N}_{2} \mathrm{O}$ Nitrous Oxide . . . 19

7. Analytical Results for Fll . . . . . . . 20

8. Analytical Results for Fl2 . . . . . . . . 21

9. Youden Plot Data........... . . 24

\section{FIGURES}

1. Schematic Diagram of System for Filling Sample. 30 Cylinders

2. Youden Plot of Data for Nitrous Oxide. . . . . 31

3. Youden Plot of Data for Trichlorofluoromethane. 32 $(\mathrm{F}-11)$

4. Youden Plot of Data for Difluorodichloromethane. 33 $(\mathrm{F}-12)$ 
EVALUATION OF METHODOLOGY FOR ANALYSIS OF HALOCARBONS IN THE UPPER ATMOSPHERE: PHASE I

Fina1 Report, March 1978

\section{ABSTRACT}

This report describes the results of a collaborative test to evaluate the state-of-the-art of measurement of the concentrations of halocarbons and nitrous oxide in the upper atmosphere. The collaborative test was the first phase of a program intended to improve the reliability of measurement of atmospheric halocarbons. A pair of test samples, differing only slightly in concentration was sent to each of sixteen laboratories. Statistical analysis of the results reported by each laboratory indicates systematic differences between laboratories which are significantly larger than within laboratory precision.

\section{INTRODUCTION}

The persistence of certain anthropogenic substances in the environment has generated concern over the long range effects which such substances might have on the health and well being of future generations. The relatively inert halocarbons, which are largely man made, have increased in use to the extent that they appear to constitute a permanent component of the atmosphere. The reaction of these materials with the environment at the earth's surface appears to be of little consequence and the health hazards of concentrations many fold greater than currently exist could be easily tolerated. However, as time passes these substance may diffuse 
in increasing quantities from the troposphere to the stratosphere where reactions with the ozone layer are quite likely to occur. The ultimate effect of such reactions has been the subject of much speculation and controversy. However, if a prudent course is to be followed, to halt, or reverse, the possible trend to increasing halocarbon concentrations in the atmosphere, the time frame in which decisions must be made requires that accurate assessment of the current conditions of the atmosphere, relative to these compounds, must be made within a few years. Measurements must be made over a wide area of the earth's surface and for a period of time sufficient to quantify trends. Such measurements obviously cannot be made by a single individual or laboratory but are, and will be, made by many groups. These measurements must be relatable one to another if valid conclusions are to be drawn from them.

Concern for the measurement problem resulted in a workshop held at the National Bureau of Standards at Boulder, jointly sponsored by the National Bureau of Standards, National Aeronautics and Space Administration, and the National Science Foundation. The goal of the workshop was to establish increased confidence in the halocarbon data measurements [1], and to this end a program was suggested which involved three basic phases. These were an assessment of the current state-of-the-art of halocarbon measurements, recomendations for changes in the measurement procedures based on the evaluation of the state-of-the-art, and finally the production and distribution of reference materials which would allow comparability between all laboratories making such measurements.

This report summarizes the results of the first phase and the conclusions drawn from the results have already been 
used to solidify the course which the second and third phases will follow.

The purpose of the first phase of the program was to determine the state-of-the-art by means of a collaborative test conducted among the principal laboratories currently measuring atmospheric halocarbons. The test was not intended to evaluate the performance of individual laboratories, but rather was intended to reveal possible deficiencies in measurement procedures related to the compounds of interest.

The study involved the distribution to the participating laboratories of pairs of samples containing low concentrations of dichlorodifluoromethane (F-12) and trichlorofluoromethane (F-11). In addition, the samples contained nitrous oxide, which was considered to be of some importance to many of the participants. The samples were prepared and analyzed to assure that each pair of samples was identical to all other pairs and that the difference between each sample in a pair was constant throughout the entire set. It was further necessary to be certain that the concentration remained the same in each sample throughout the period of the test.

A tentative value for each constituent has been assigned based on calibration procedures utilized at NBS during the preparation of the samples. These values have been included in this report but only with the same status as results from any other participating laboratory; no greater weight has been assigned than was given to other participants.

\section{PREPARATION OF SAMPLES}

The samples were prepared by compressing non-urban air into fifty cleaned aluminum cylinders to a pressure of about 
$5.5 \times 10^{3}$ kilopascals ( $800 \mathrm{psi}$ ). The air being compressed was periodically analyzed to be certain that it contained reasonable amounts of the components of interest. Air, free of detectable quantities of nitrous oxide and the halocarbons was then added to twenty five of the cylinders to a final pressure that resulted in a dilution of about 16 percent of the nitrous oxide and halocarbons originally present. The samples were then analyzed for the concentration of nitrous oxide, halocarbons and for other halogenated hydrocarbons.

The cylinders were filled to a relatively high pressure in order that adequate samples would be available both for the initial and final analysis at NBS and for the participants without the occurrence of a large pressure drop in the cylinder which might affect the concentration of the components because of desorption from the walls.

\section{CYLINDERS AND CYLINDER PREPARATION}

New, unused aluminum cylinders were cleaned, valved, and evacuated under the direct supervision of NBS by a commercial supplier. A valve thread lubricant was used, which was reported by the manufacturer to contain no halogens. The cylinders were filled preliminarily to a pressure of about $6.9 \times 10^{3} \mathrm{kPa}(1000 \mathrm{psi})$, and the contents were examined. A large peak due to trichlorethylene was observed. It was subsequently determined that this compound had been used by the supplier to degrease the valves. Attempts were made to remove the material by blowing down the cylinder, heating the exterior with steam, and flushing and evacuating several times. The treatment reduced the amount of trichlorethylene but not to a level that might not interfere with subsequent analyses. 
Consequently, all of the cylinders were blown down and the valves disassembled. The valve components were washed with ethanol and vacuum dried at $130{ }^{\circ} \mathrm{C}$ for 3 hours. The valve bodies were not removed from the cylinder but were heated in place with a heat gun.

The valves were reassembled and flushed with room air followed by evacuation to a pressure of less than $1 \mathrm{kPa}(0.01$ atmosphere). This treatment was repeated several times after which a few cylinders were filled with air free of trichlorethylene. These cylinders were examined over a period of several days and it was determined that the treatment substantially reduced the trichlorethylene contamination. The filling of the cylinder with the final samples was then begun.

\section{FILLING THE CYLINDER}

The cylinders were filled using the system shown in Figure 1. The air was drawn through a $12.7 \mathrm{~mm}(1 / 2$ in) copper tube mounted vertically on the roof of Building 236 (Hazards Laboratory) and projecting 3 meters above the roof top. The Hazards Laboratory is located at the southern edge of the NBS property in a relatively isolated location.

There are no activities in the building which would contribute either nitrous oxide or halogenated hydrocarbons to the atmosphere in the vicinity of the building. The surrounding area is primarily open field and woodlands with no regularly traveled roads in the vicinity.

The $12.7 \mathrm{~mm}$ (1/2 in) copper probe was connected to a $9.5 \mathrm{~mm}$ ( $3 / 8 \mathrm{in})$ copper tube leading from the roof to the interior of the building at ground level. The probe and lead line were both heated along their entire lengths with a 
heat gun while air was drawn through them prior to use. Two coarse particle filters were inserted in parallel to protect the pump. The parallel installation was simply to reduce the pressure drop in the inlet line. Two small stainless steel diaphragm pumps were installed at the end of the lead line to feed the main compressor inlet at $200 \mathrm{kPa}$ (30 psi).

The main compressor was a diaphragm pump in which the sample contacts no lubricant nor any material other than stainless steel, copper, and brass. The output of the main pump was fed into a pair of low pressure stainless steel cylinders which served to remove a large part of the water from the sample. The compressed air, after water separation, passed into a bank of four large steel cylinders of $42 \mathrm{~L}$ capacity $\left(1.5 \mathrm{ft}^{3}\right)$. These cylinders were filled to a pressure of about $2.07 \times 10^{3} \mathrm{kPa}(300 \mathrm{psi})$ as the first step. The pressure in the water separator during the filling was maintained at $2.07 \times 10^{3} \mathrm{kPa}(300 \mathrm{psi})$ in order to prevent condensation in the steel cylinder. When the pressure. in the steel cylinder reached $2.07 \times 10^{3} \mathrm{kPa}(300 \mathrm{psi})$ the main pump was shut-off and the various valves shown were opened and closed to direct the air in the steel cylinder to the inlet of the main pump while the outlet was routed to the high pressure water scrubber, then to the drier, and finally to the bank of 50 small cylinders. The outlet of the main compressor was maintained at about $1.4 \times 10^{4} \mathrm{kPa}(2000 \mathrm{psi})$ up to the valve beyond the high pressure drier. When the pressure from the steel tanks at the inlet of the main compressor dropped to $1000 \mathrm{kPa}$ (150 psi) the compressor was stopped and the valves were readjusted to refill the steel cylinders to $2.07 \times 10^{3} \mathrm{kPa}(300 \mathrm{psi})$. This sequence was repeated until the pressure in the 50 small cylinders reached $5.5 \times 10^{3} \mathrm{kPa}(800 \mathrm{psi})$. The time required was about one 
week so that the samples represent the integrated concentration in the atmosphere during this period of time.

After each filling of the 50 small cylinders, the water accumulated in the high pressure scrubber was blown off through the valve at the bottom of the scrubber.

The high pressure dryer was filled with anhydrous calcium sulfate. The possibility that calcium sulfate at high pressure might adsorb trace materials from the sample was investigated. It was found that some slight losses occurred, but the bulk of the material passed through the dryer without significant change in concentration.

After the fifty small cylinders were filled to $5.5 \mathrm{x}$ $10^{3} \mathrm{kPa}(800 \mathrm{psi})$, twenty five were removed from the manifold. The remaining twenty five were diluted to a pressure of about $6.4 \times 10^{3} \mathrm{kPa}$ (925 psi) with air free of nitrous oxide and the halocarbons F-11 and F-12. The dilution ratio is approximately 1.16 to 1 . The concentration of the three substances in the diluted set of twenty five samples should therefore be about 0.86 times that of the undiluted samples.

\section{HOMOGENEITY VERIFICATION}

\subsection{Measurement Method and Standards}

The analytical instrument used for the verification of homogeneity and for subsequent assignment of a tentative value to the samples was a commercial gas chromatograph equipped with a ${ }^{6}{ }^{3} \mathrm{Ni}$ electron capture detector. The detector was operated at a temperature of $360^{\circ} \mathrm{C}$. A number of different column materials were tried, including activated alumina, Porapak Q, Chromasorb 102 and several types of porous 
glass beads. All of these were satisfactory to some extent, but the column found to give the best separation of F-11 with a reasonably short retention time was a $0.92 \mathrm{~m} \times 3.2 \mathrm{~mm}$ (3' $x$ 1/8") stainless steel column packed with porous glass beads, $80 / 100$ mesh, operated at $80^{\circ} \mathrm{C}$. A $2.8 \mathrm{~m} \mathrm{x} 3.2 \mathrm{~mm}$ ( $\left.9^{\prime} \times 1 / 8^{\prime \prime}\right)$ stainless steel column packed with porous silica glass beads, $4 \times 10^{-10} \mathrm{~m}(40 \AA)$ pore size, $80 / 120$ mesh, and operated at $90{ }^{\circ} \mathrm{C}$ was used for F-12, and for nitrous oxide the same column was used but the temperature was reduced to $80{ }^{\circ} \mathrm{C}$. Full details of the analytical procedures may be obtained directly from the authors.

It is possible to detect all three compounds under one set of conditions on a single chromatogram. However, because the purpose of these analyses was to establish the relationship of the concentration of each compound in each sample to all other samples, conditions were chosen independently for each compound such that the condition would give the greatest precision for that compound. Therefore, while these particular columns might not be ideal for determination of all three components at once, it was possible to adjust conditions to obtain good separation, to reduce overlap and tailing and to produce sharp narrow peaks.

Attempts were made to measure the areas of the peaks electronically but it was found that the peak height was in general more reproducible and all of the values relating samples to each other are based on manual measurement of peak heights.

The carrier gas was a mixture of 5 percent methane in argon. Flow rates were not set precisely but were controlled by precise adjustment of the column head pressure to a value of $414 \mathrm{kPa}$ (60 psi). 
The values reported by NBS, as a participant in the collaborative study, for the concentrations of F-11 and F-12 are based on comparison of the internal standard of each lot, $A$ and $B$, with standards prepared by static dilution of a mixture containing the two halocarbons at concentrations in the parts per million range. The starting mixture contained F-11 at 20 ppm and F-12 at 200 ppm. These were diluted to the parts-per-trillion range. In addition, a dynamic dilution system was used to dilute the starting mixture to the range of the samples in order to define roughly the response characteristics of the detector. Further work is in progress to refine the dilution system and to prepare independent standards starting with analyzed samples of the two halocarbons.

The values for nitrous oxide are based on comparison of the internal standard of each set with standards prepared by static dilution of pure nitrous oxide and nitrogen.

\subsection{Homogeneity Data}

The entire set of samples was analyzed to determine the homogeneity. This was done by selecting one sample at random from each set of twenty five samples and comparing all other samples in the set to that sample. All twenty five samples in each set were compared for the halocarbon content. The procedure in general consisted of alternating analyses of the sample chosen at random, referred to as the "internal standard", with several of the samples. Instrumental drift of the chromatograph was compensated for by interpolating between standards to determine the instrument response to the standard at the time when each sample was analyzed. The signal for each sample was then divided by the signal for the internal standard. This ratio was multiplied by the tentative concentration assigned to the 
Table 1. Analysis of Halocarbon in Each Sample, Concentration in Parts per Trillion by Mole

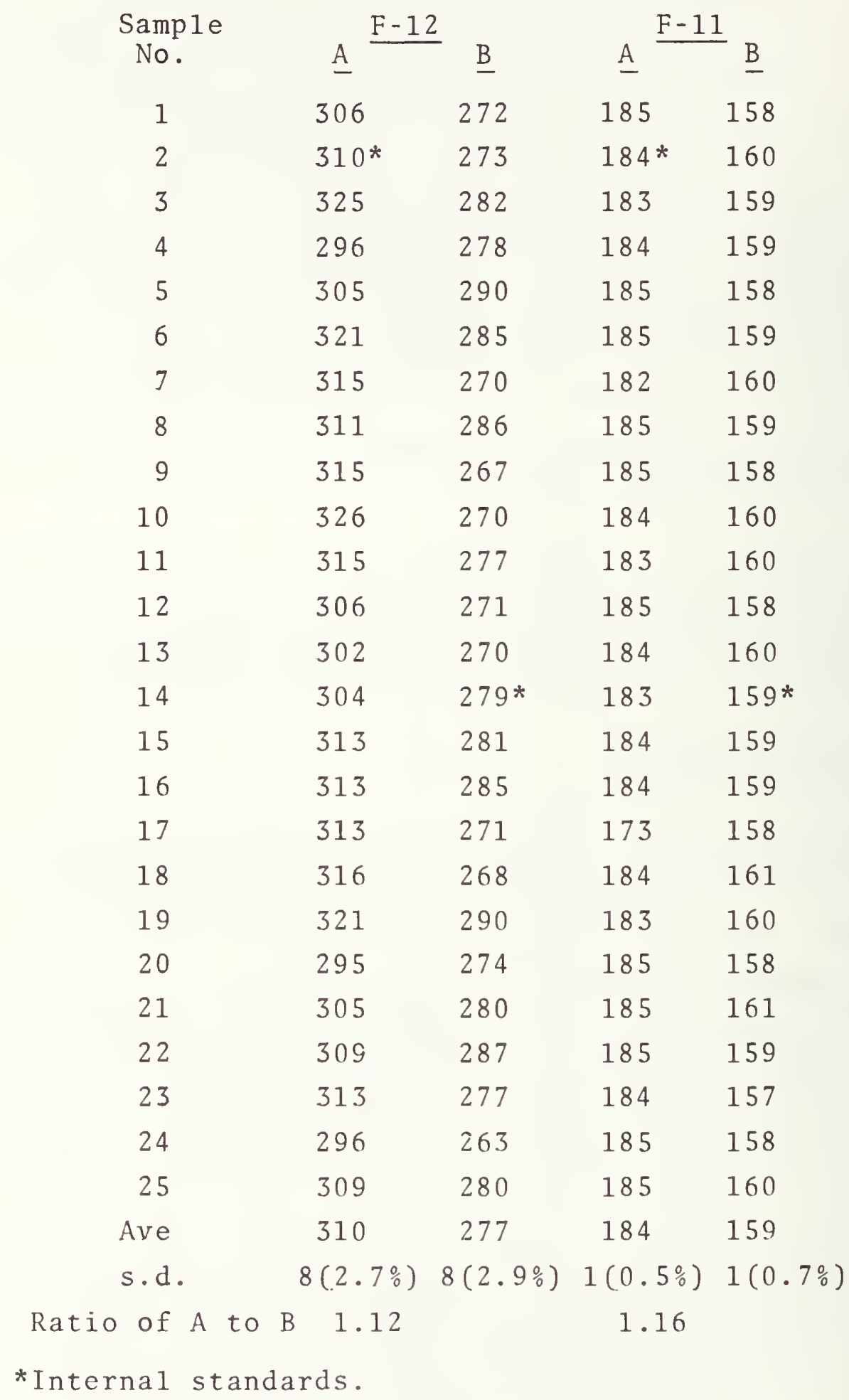


internal standard and the product was considered the tentative value for the analysis but not necessarily for the concentration. The values for the analysis of each sample in each lot for each halocarbon is shown in Table 1 . The lot marked "A" is the undiluted sample and "B" is the diluted sample.

The standard deviation is based on all samples except the internal standard and sample 17-A. The value for F-11 in sample 17-A is obviously well below the average and well outside of the limits of error and it has been excluded from the exercise.

Table 2 is a summary of the results obtained on replicate analysis of several samples of both A and B series. The standard deviation reflects the larger uncertainity in the analysis for F-12 and confirms the homogeneity, within the limits shown, of the concentration of F-12 and F-11 in the two sets of samples. 
Table 2. Replicate Analyses of Several Samples in Both A and B Series

Concentration in Parts per Trillion by Mole

\begin{tabular}{|c|c|c|c|c|c|c|c|c|}
\hline \multirow[b]{2}{*}{ Sample No. } & \multicolumn{3}{|c|}{$\mathrm{F}-12$} & \multicolumn{5}{|c|}{$\mathrm{F}-11$} \\
\hline & $2 \mathrm{~A}$ & $14 \mathrm{~B}$ & $2 \mathrm{~A}$ & Al8 & $\mathrm{A} 21$ & B5 & $\underline{B} 13$ & $\underline{B 19}$ \\
\hline & 300 & 287 & 303 & 182 & 187 & 158 & 160 & 157 \\
\hline & 304 & 270 & 306 & 185 & 182 & 158 & 158 & 163 \\
\hline & 318 & 282 & 317 & 182 & 186 & 159 & 162 & 160 \\
\hline & 318 & 266 & 314 & 183 & - & 157 & - & - \\
\hline & 292 & 277 & - & - & - & - & - & - \\
\hline & 309 & 281 & - & - & - & - & - & - \\
\hline & 308 & 276 & - & - & - & - & - & - \\
\hline & 306 & 279 & - & - & - & - & - & - \\
\hline & 317 & 264 & - & - & - & - & - & - \\
\hline & 316 & 275 & - & - & - & - & - & - \\
\hline & 321 & 287 & - & - & - & - & - & - \\
\hline & 311 & 273 & - & - & - & - & - & - \\
\hline & 311 & 278 & - & - & - & - & - & - \\
\hline & 317 & - & - & - & - & - & - & - \\
\hline & 301 & - & - & - & - & - & - & - \\
\hline & 310 & - & - & - & - & - & - & - \\
\hline $\begin{array}{c}\text { Average } \\
\text { s.d. }\end{array}$ & $\begin{array}{l}310 \\
8(2.6 \%)\end{array}$ & $\begin{array}{l}277 \\
7(2.5 \%)\end{array}$ & $\begin{array}{l}310 \\
7(2.1 \%)\end{array}$ & $\begin{array}{l}183 \\
2(0.9 \%)\end{array}$ & $\begin{array}{l}185 \\
3(1.4 \%)\end{array}$ & & $\begin{array}{l}160 \\
2(1.2 \%)\end{array}$ & $\begin{array}{l}160 \\
3(1.8 \%)\end{array}$ \\
\hline
\end{tabular}

The values for F-12 in Sample $2 \mathrm{~A}$ were obtained by comparison to independent standards in much the same manner as the samples in both $A$ and $B$ were analyzed. The two series for Sample $2 \mathrm{~A}$ were obtained at different times. 
The analysis of nitrous oxide was performed in the same manner as for the halocarbons except that not all of the samples were analyzed before distribution to the participants. The homogeneity among samples relative to the halocarbons, and the results obtained on analysis of eight samples for nitrous oxide indicated a similar degree of homogeneity among all three components of interest. The results for nitrous oxide are shown in Table 3 .

Table 3. Analysis of Nitrous Oxide in Several Samples, Concentration in Parts per Billion by Mole

Sample No.

1

2

3

7

12

14

20

Ave

s.d.

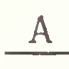

302

299

298

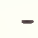

298

297

299

$2(0.6 \%)$

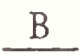

259

263

255

259

$4(1.5 \%)$

The uncertainty of the averages is less than the uncertainty of the average for replicate analyses of a single sample which indicates that within the limits shown, each set, $A$ or $B$ is homogenous within itself. 


\section{STABILITY OF SAMPLES}

Assurance that the samples distributed for analysis remain stable in concentration is critical to the entire purpose of the collaborative test. Confidence that the samples are stable can be deduced from several sources. First, the homogeneity of each lot indicates that no random and rapid losses are occurring. In general, loss of a component of a gas mixture in a cylinder is dependent on the condition of the individual cylinder, and if such losses are occurring in a number of cylinders, the concentrations measured are different from each other by a greater amount than the known imprecision of the method of analysis. The larger the period of time between transfer of the sample into the cylinder and the initial analysis, the greater will be the range of values obtained. The samples in each lot were "packaged" at least three weeks before the analyses were completed and no evidence was found of instability of the samples.

A second and more valuable source of information was obtained by reanalysis of samples returned by the participants. Unfortunately, all samples were not returned and several of those that were returned were either contaminated or were empty. Table 4 is a summary of the results obtained on analysis for the halocarbons after return of the indicated samples. 
Table 4. Analysis of Halocarbons in Samples after Return, Concentration in Parts per Trillion by Mole

$$
\text { F }-12
$$

Sample No.

2

5

8

9

10

13

14

18

20

22

23

24

25

Ave

s.d.

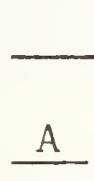

295

324

304

315

317

308

302

310

307

312

302

317

322

310

$9(2.7 \%)$

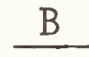

286

283

281

274

270

275

288

273

265

278

276

281

278

$7(2.4 \%)$
F- 11

A

B

183

182

157

181

158

186

160

183

159

159

185

156

180

160

183

155

182

162

183

161

182

158

183

159

$2(1.3 \%)$ 
The averages and uncertainties are essentially identical to those obtained on the initial analysis and the conclusion may be made that the samples did not change in composition between the initial analysis and the time of analysis by the participants.

Samples which were returned but which are not included in the results are samples numbered 4 and 11 . Both number 4 sample cylinders were returned with the valves opened. Sample 11 was found to be contaminated with a material which seriously interfered with, and added to, the peak due to F-11. The contaminant was apparently in the valve and fluctuated widely in concentration during a series of analyses of the sample. The values reported by the participant, however, appear to be valid and have been confirmed by his subsequent analysis of a second set of samples for which the results were identical to the analysis of the first set.

There is no evidence of loss of nitrous oxide in the samples between the initial analysis of several samples and the time of analysis of the samples that were returned. The results obtained after return of the samples are shown in Table 5 . 
Table 5. Analysis of Samples for Nitrous Oxide After Return. Concentration in Parts per Billion by Mole

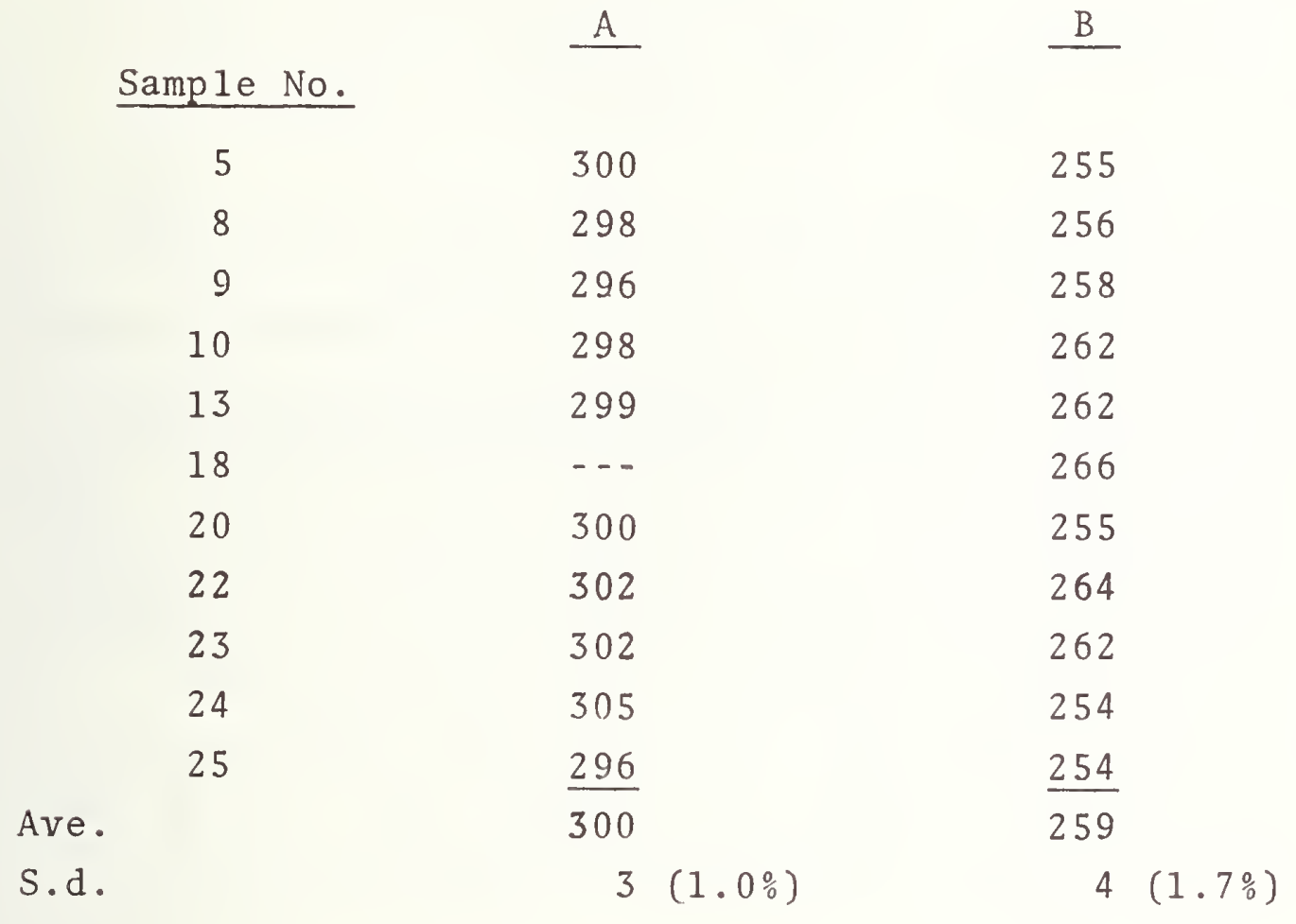

The averages agree quite well with the values prior to distribution and the conclusion concerning stability relative to the halocarbon apply equally to nitrous oxide.

\section{PARTICIPATION}

Sixteen laboratories participated in these collaborative tests. Letters of invitation were issued to all attendees at the "Workshop on Halocarbon Analysis and Measurement Techniques" as well as a number of other laboratories known to be actively engaged in measurements of halocarbons in the atmosphere. Most all of those invited expressed interest but some were unable to participate within the time period designated for the Phase I tests. 
The laboratories that met the requirements for participation are listed in the Appendix. They are believed to represent groups of similar capability, hence their participation should furnish valuable information on the state of the art of measurement of the components of interest.

Each participating laboratory was sent a set of two test samples identified as FXA and FXB together with a serial number as already described. The laboratories were requested to make a series of measurements on each sample, using their own calibration methods and measurement procedures. They were instructed to report the mean value, the number of measurements, and standard deviation of a single measurement for each component. They were also requested to describe the method of calibration and the measurement procedure used. While each laboratory was encouraged to measure all three components of interest, $\mathrm{N}_{2} \mathrm{O}, \mathrm{F} 11$ and $\mathrm{F} 12$, they were not excluded from the test if they could not measure all of them.

\section{RESULTS OF COLLABORATIVE TEST}

The analytical results reported by the collaborating laboratories are summarized in Tables 6,7 and 8 . The arbitrarily assigned laboratory designation is the same for each set of measurements. The various columns list the number of measurements, $\mathrm{n}$, made by the laboratory, and the average analytical result, $\bar{x}$. The 95 percent confidence interval for the average value was computed when possible, using the standard deviation of a single measurement, $s$, as reported by the laboratory. The tables also include the ratio of concentrations FXA/FXB computed from the average values. In addition, the consensus values, based on all of the measure- 


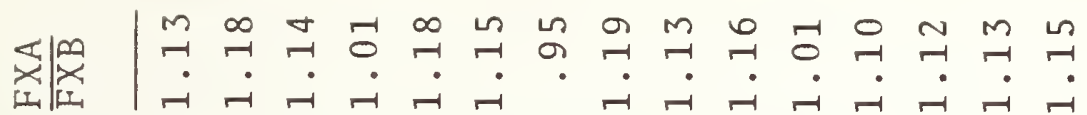

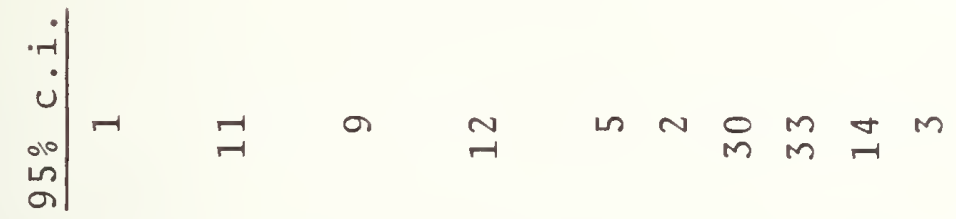

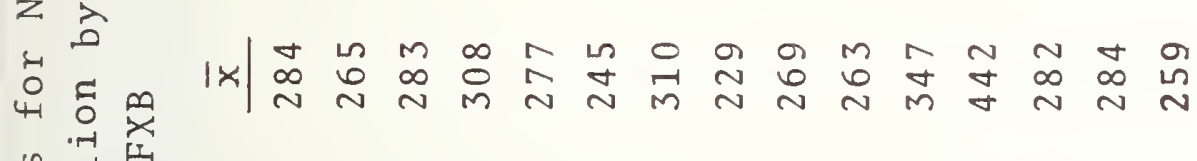

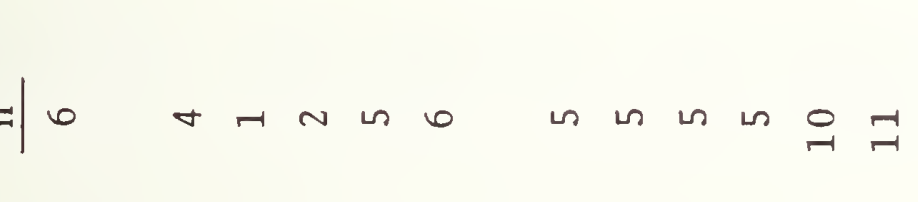

胥 


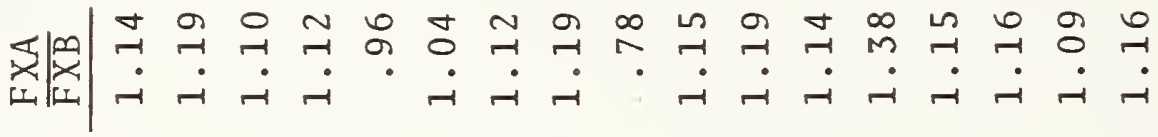

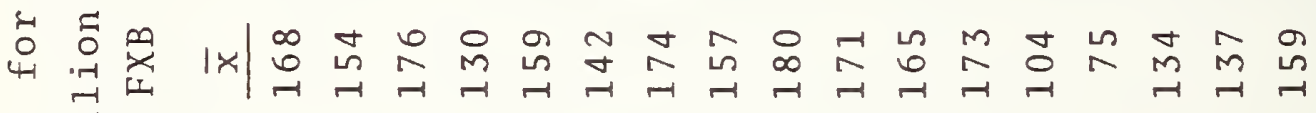

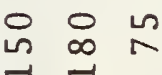

on -1

$\stackrel{2}{2}$

is

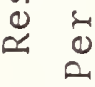

$\approx \mid a$

$\forall \infty \rightarrow a \sim m o$

$\ln 0$ in a $N$

$\tilde{\overbrace{}}$

का क

$\bigcup_{\substack{\pi \\ 0}}^{+\pi}$

$+\pi$

苟.

₹

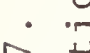

$\sim$

$\stackrel{0}{2}$

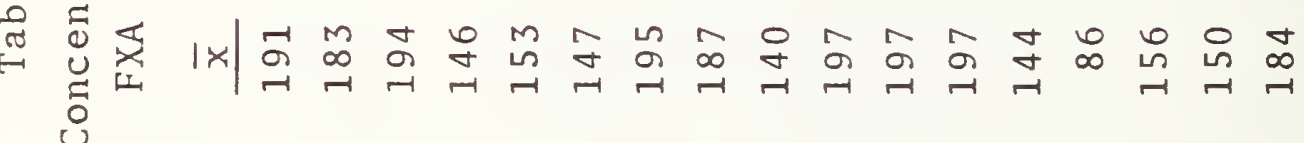

a

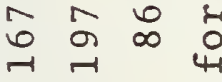

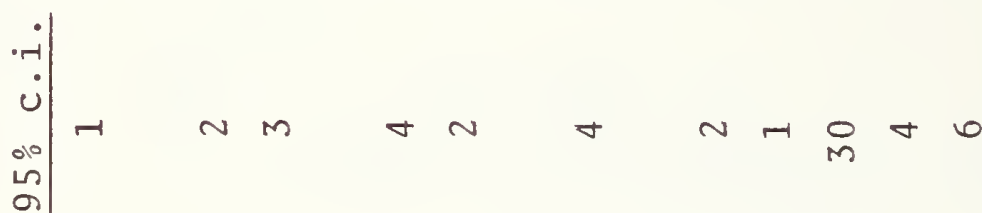

$\stackrel{2}{-1}$

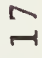

.

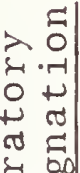

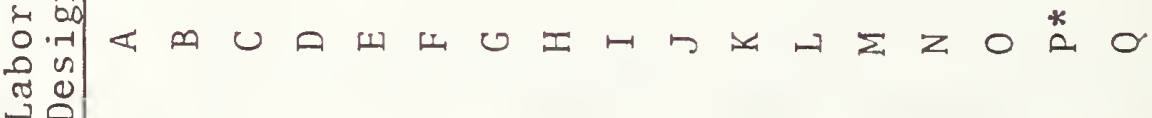




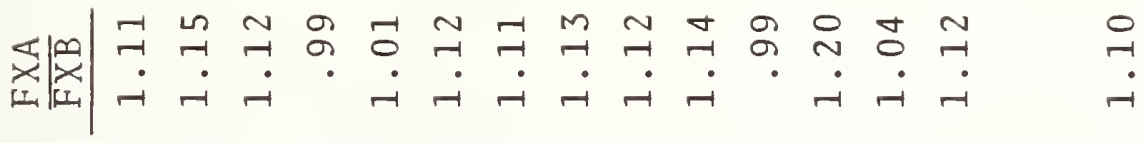

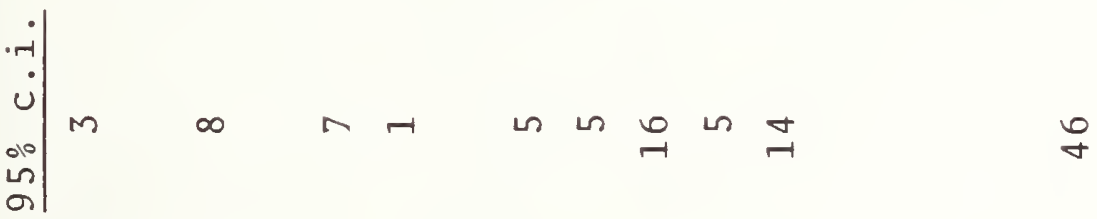

至

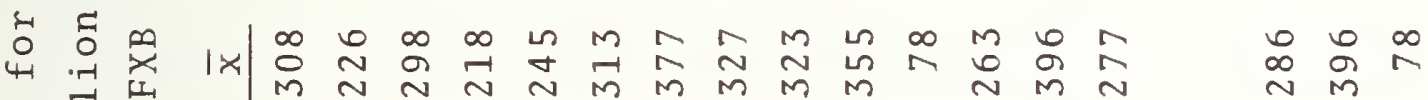
$\stackrel{2}{\sim} \underset{1}{2}$

$\stackrel{0}{\approx}$

$A \mid r$

$\infty$

a in

$\ln \underset{\pi}{\pi} \cos$

$\underset{7}{\square}$

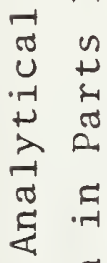

.

$\infty \stackrel{+\infty}{+\infty}$

0

满

造

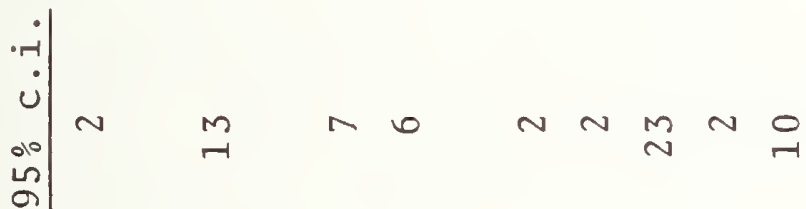

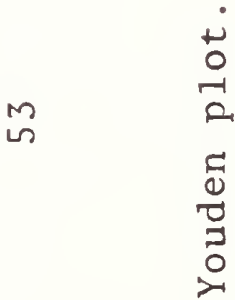

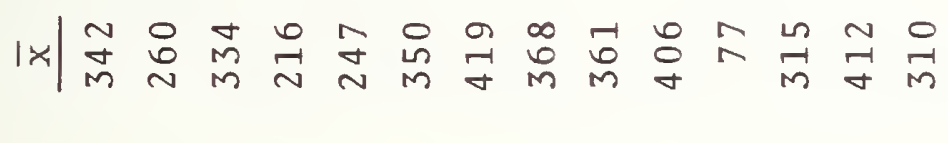

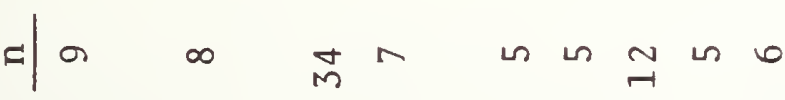

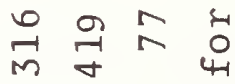

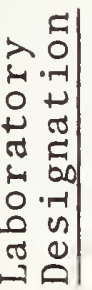

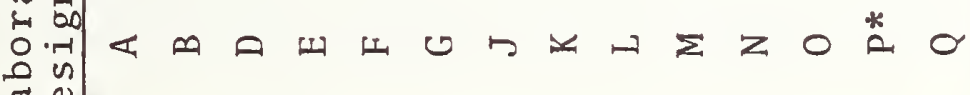

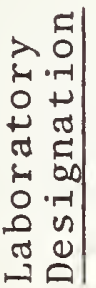

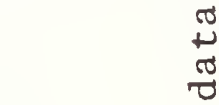

$\stackrel{+}{\square}$

.

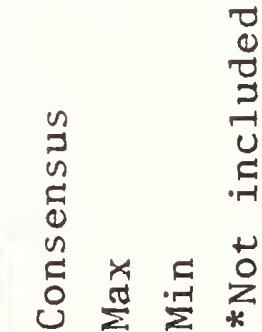


ments are reported as well as the maximum and minimum values that were received from the participants.

The data were analyzed on the basis of the Youden plot (2) as generalized by Mandel and Lashof (3). This procedure was proposed by Youden to distinguish between random flucuations of sample and/or measurement, and systematic errors. Each laboratory is given a set of two samples of similar composition and the result obtained on one is plotted with respect to the result reported for the second sample. If only random fluctuations of measurement and/or sample composition are present, the data should be circularly distributed about the intersection of the expected values for the samples. When significant systematic errors are present (bias) the points should be distributed in an elliptical envelope and indeed along a $45^{\circ}$ angle with the $x, y$ axes.

In the elliptical distribution, the perpendicular distance of a point to the major axis of the ellipse is related to the random error, while the distance of the intersection of the perpendicular to the coordinates of the expected value is related to bias. Accordingly, the length of the major axis is related to the "between laboratory variability", and the length of the minor axis to the "material-1aboratory interaction."

Experience has shown that a circular distribution is rarely obtained but most frequently an elliptical distribution is observed. Ellipses in which the ratio of the major axis to the minor axis is greater than 2, are considered to be significant and indicate the existence of systematic errors in the results reported by the collaborating laboratories. 
The "best fitting ellipse" was computed by the procedure developed by Mandel and Lashof (3) and the parameters are given in Table 9 and are graphically presented in figures 2,3 , and 4. The data from one laboratory was received after the machine fitting of the ellipses. These values are included in the values shown in Tables $6-8$ but were not used in the Youden plots. The grand mean values indicate the consensus values for the samples, in which equal weight is given to each reported value. Values are computed for the major axis and the minor axis of ellipses that would be expected to contain 99 percent and 95 percent, respectively, of all values that would be reported by a very large number of laboratories of which the present group is representative.

It will be noted that the ratios of these axes are 5.35 for $\mathrm{N}_{2} \mathrm{O} ; 3.12$ for $\mathrm{F} 11$, and 14.8 for F12. These values are considered to indicate that systematic errors predominate with respect to random errors in each case. The graphical plots confirm this conclusion. However, it should be emphasized that no rigid statistical parameters should be inferred from the Youden-plot analysis. While the elliptical distribution indicates the existence of significant bias between values reported by the various laboratories, the number of participants and the way the test was conducted precludes the calculation of within-laboratory and betweenlaboratory variances. Moreover, since each laboratory used its own-developed techniques and procedures, a detailed analysis of such variance is not possible. The only conclusion that can be drawn is that significant systematic errors do exist in results reported by various laboratories and procedures need to be developed to minimize them, if data reported by various laboratories are to be intercompared. 


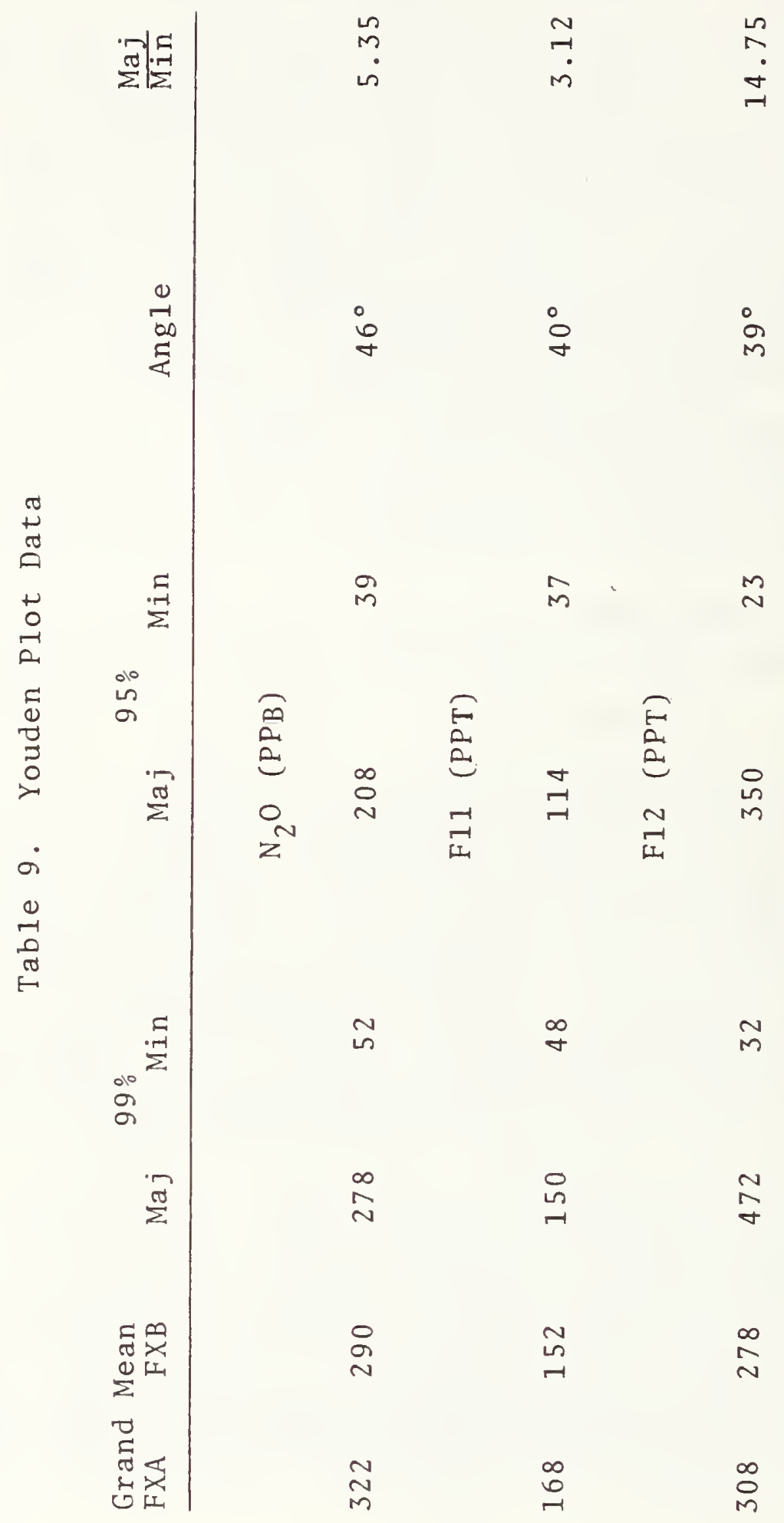


The observed ratios of the concentration levels for each constituent are of some interest, inasmuch as the lower concentration sample was prepared by dilution of the one of higher concentration. On the basis of manometric measurements, a ratio of 1.16 would have been expected. However, it is possible that the diluent air was not as pure as believed, hence departures from the expected ratio are possible.

It is interesting to note that the consensus values give a ratic of FSA/FSB of between 1.10 and 1.12 for a 11 three substances. The ratios obtained at NBS during the homogeneity studies were: for $\mathrm{N}_{2} \mathrm{O}-1.15$; for F11- 1.16 , for F12 - 1.12. The NBS ratios for $\mathrm{N}_{2} \mathrm{O}$ and $\mathrm{F} 11$ are in agreement with the expected values within the uncertainties of measurement. The ratio found for the F-12 measurements is lower than expected and may indicate the presence of F-12 in the diluent gas. However, the concentration of F-12 that would be necessary to account for the discrepancy would appear to be unreasonable. In any event, a significant departure from the expected ratio of 1.16 is believed to constitute a reason to examine measurement procedures for previously unsuspected measurement problems.

\section{CONCLUSION}

The overall conclusion that may be drawn from these collaborative measurements of atmospheric samples is that constituents occurring at the parts-per-trillion level of concentration $\left(\simeq 6 \mathrm{pg} / \mathrm{m}^{3}\right)$ can be measured in a given laboratory with a precision of 10 percent or better. However, results reported by different laboratories can be expected to vary by as much as \pm 40 percent. 
This large error appears to be systematic in nature and is probably due to differences in calibrations, and/or sample handling techniques, although other causes cannot be excluded at this time. The one first stated is the most logical source of error since each laboratory would tend to minimize its own handling and measurement errors if calibration and analysis was done under similar conditions, which appears to be the situation.

In Phase II of this program we propose to repeat the collaborative tests with two additional samples and a reference sample which would be used as a benchmark for all measurements that are reported. This would eliminate the uncertainty due to variation in the composition of the calibration gases used in each laboratory.

Another useful activity that would serve to identify and minimize measurement biases, and perhaps also to improve precision, is a workshop in which all participants would meet to exchange their experiences in the measurements of these samples. Such an exchange could uncover measurement problems not generally recognized, so that improvements in technique could be adopted that would minimize these problems.

\section{ACKNOWLEDGEMENT}

This work was supported by the National Aeronautics and Space Administration and by the Office of Air and Water Measurements of the National Bureau of Standards. 


\section{REFERENCES}

1. R. A. Rasmussen, D. J. Pierotti and J. Krasnec, "Analysis of Halocarbons in the Atmosphere, Report of a Workshop," Air Pollution Control Association, 69 th Meeting, Portland, Oregon June 27-July 1, 1976.

2. W. J. Youden, "Graphical Diagnosis of Interlaboratory Test Results", Industrial Quality Control, Vol. 15, No. 11, Mä̈ 1959 .

3. J. Mandel and T. W. Lashof, "Interpretation and Generalization of Youdens Two-Sample Diagram," Journal of Quality Control, Vol. 6, No. 1, pp. 22-36, January 1974 . 


\section{APPENDIX}

\section{List of Participating Laboratories}

Dr. Ralph J. Cicorone

University of Michigan

Space Research Laboratory

Ann Arbor, MI 48109

Robert K. Stevens

Arthur I. Coleman

United States Environmental Protection Agency

Environmental Sciences Research Center

Research Triangle Park, NC 27711

H. H. Gil1

Dow Chemical USA

Michigan Division

Midland, MI 48640

Robert A. Gorski

E. I. DuPont de Nemours \& Co.

Organic Chemicals Department

Wilmington, DE 19898

Bennet J. Tyson

National Aeronautics and Space Administration

Ames Research Center

Moffett Field, CA 94035

Paul Fraser

Colin R. Ray

Commonwealth Scientific and .

Industrial Research Organization

Division of Atmospheric Physics

Aspendale, Australia

Stewart A. Penkett

UKAEA Riseau Group

Environmental and Medical Sciences Division

AERE Harwe11, Oxfordshire, ENGLAND

R. J. Lagomarsino

U. S. Energy Research and Development Administration Health and Safety Laboratory

New York, NY 10014

Paul D. Goldon

Thane Thompson

National Oceanographic and Atmospheric Administration

Environmental Research Laboratories

Boulder, CO 80302 
Lorne Elias

National Research Council of Canada National Aeronautical Establishment Ottawa, Canada K1A0R6

Hanwant B. Singh

Stanford Research Institute

Menlo Park, CA 94025

H. I. Schiff

York University

Faculty of Science

Downsview, Ontario, Canada M3J1P3

J. E. Lovelock

Bowerchalke

Salisbury, Wiltshire, England SP56BQ

R. A. Rasmussen

Washington State University

Department of Chemical Engineering

Pullman, WA 99163 


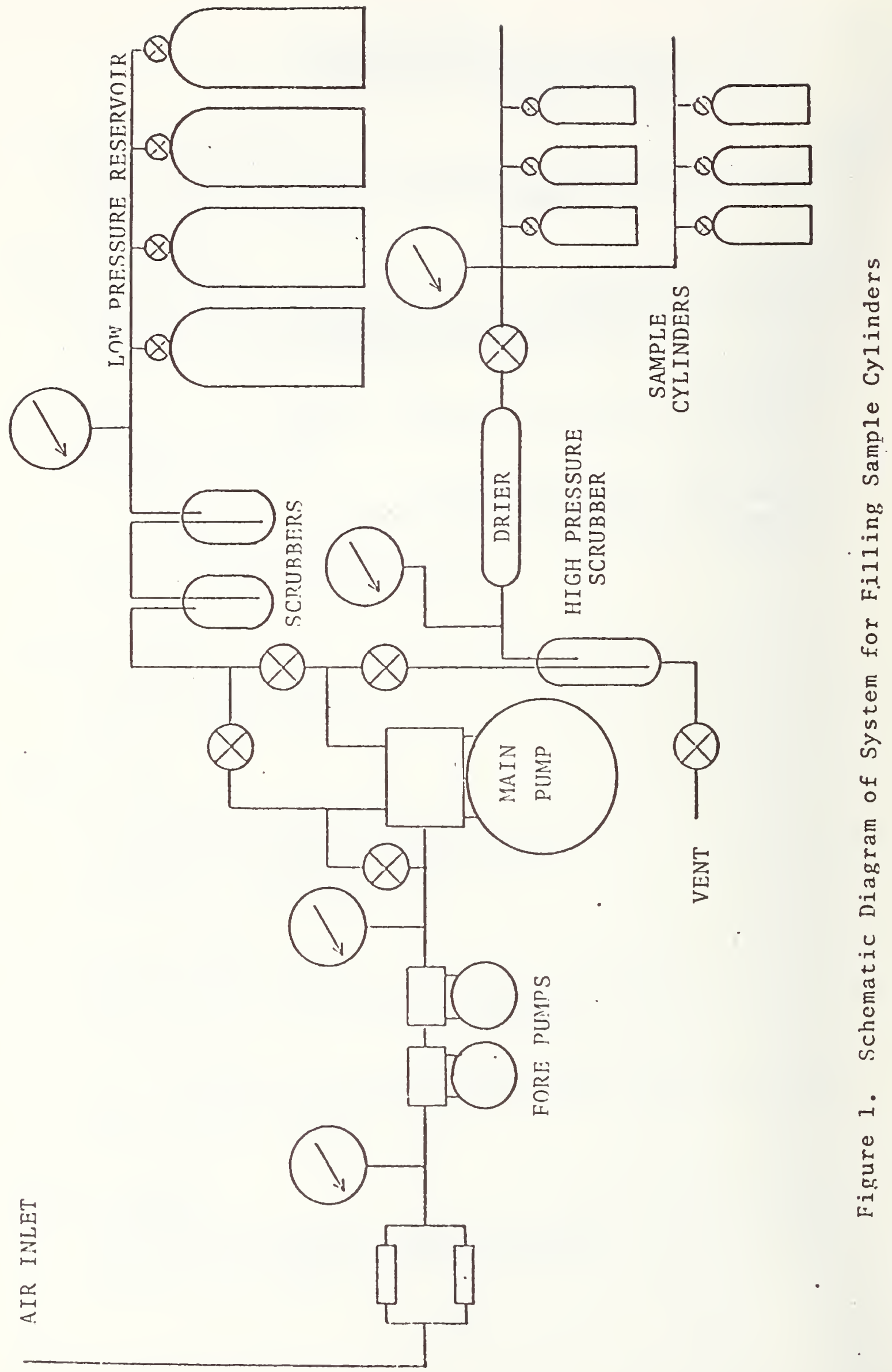




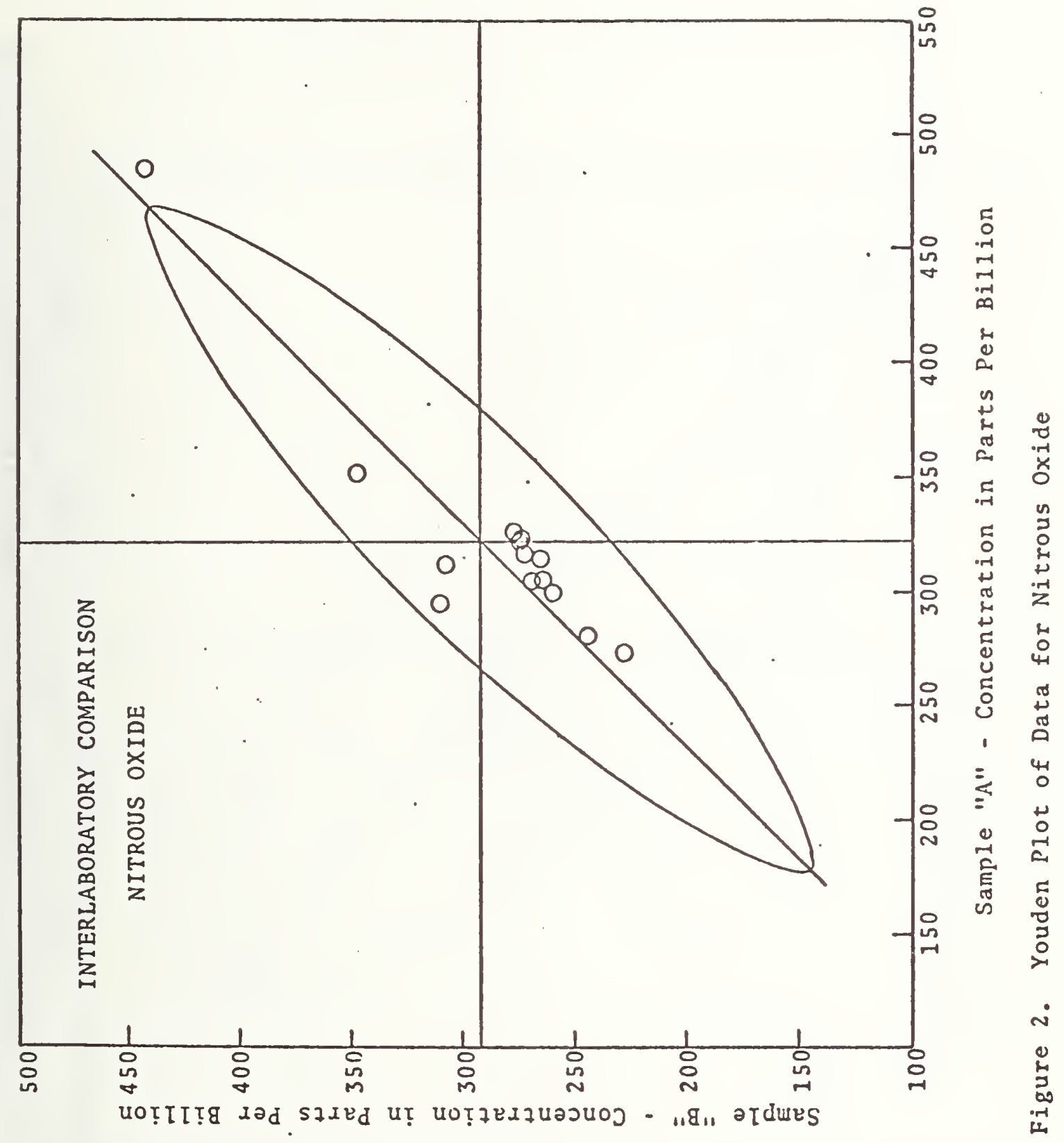




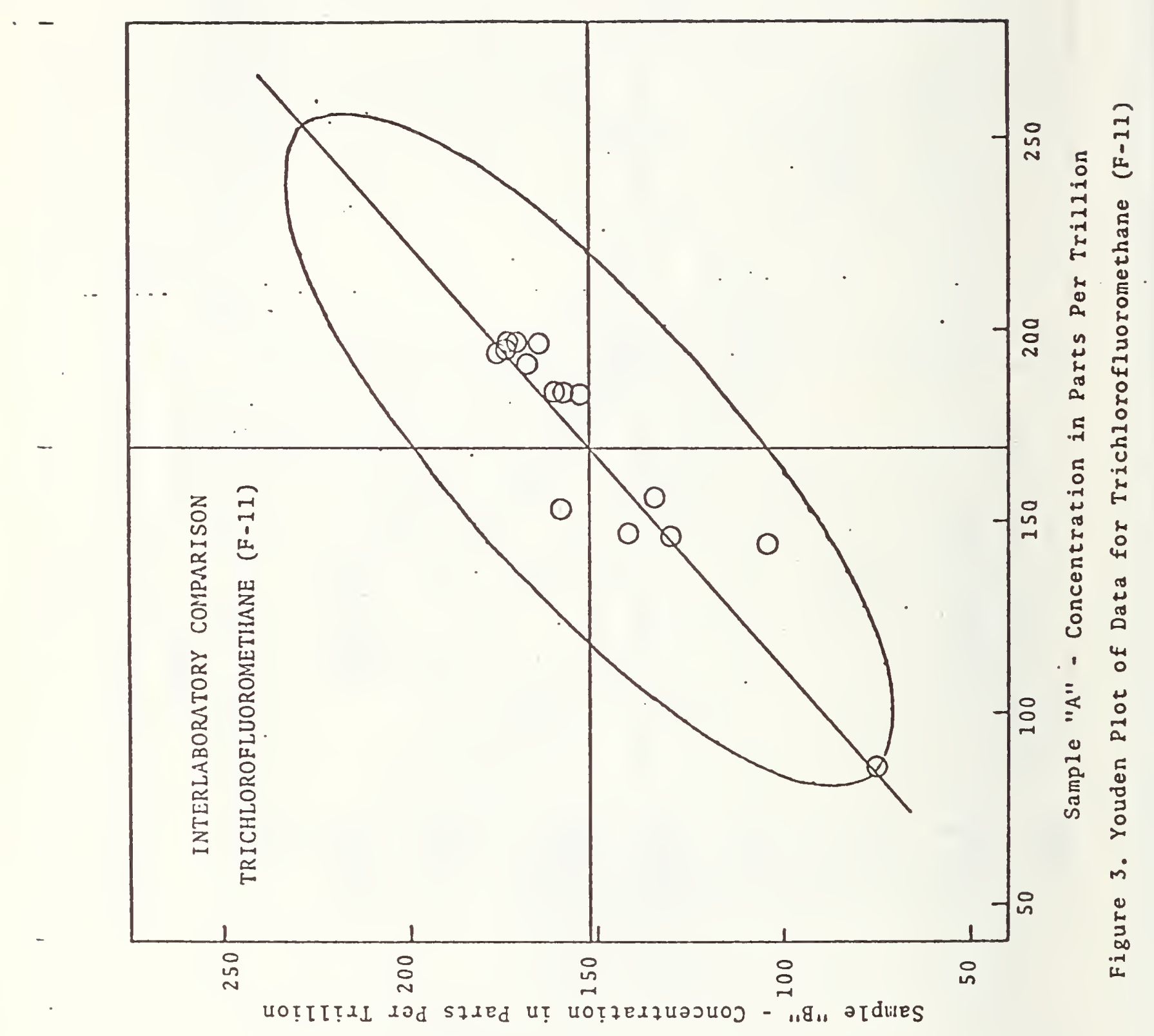




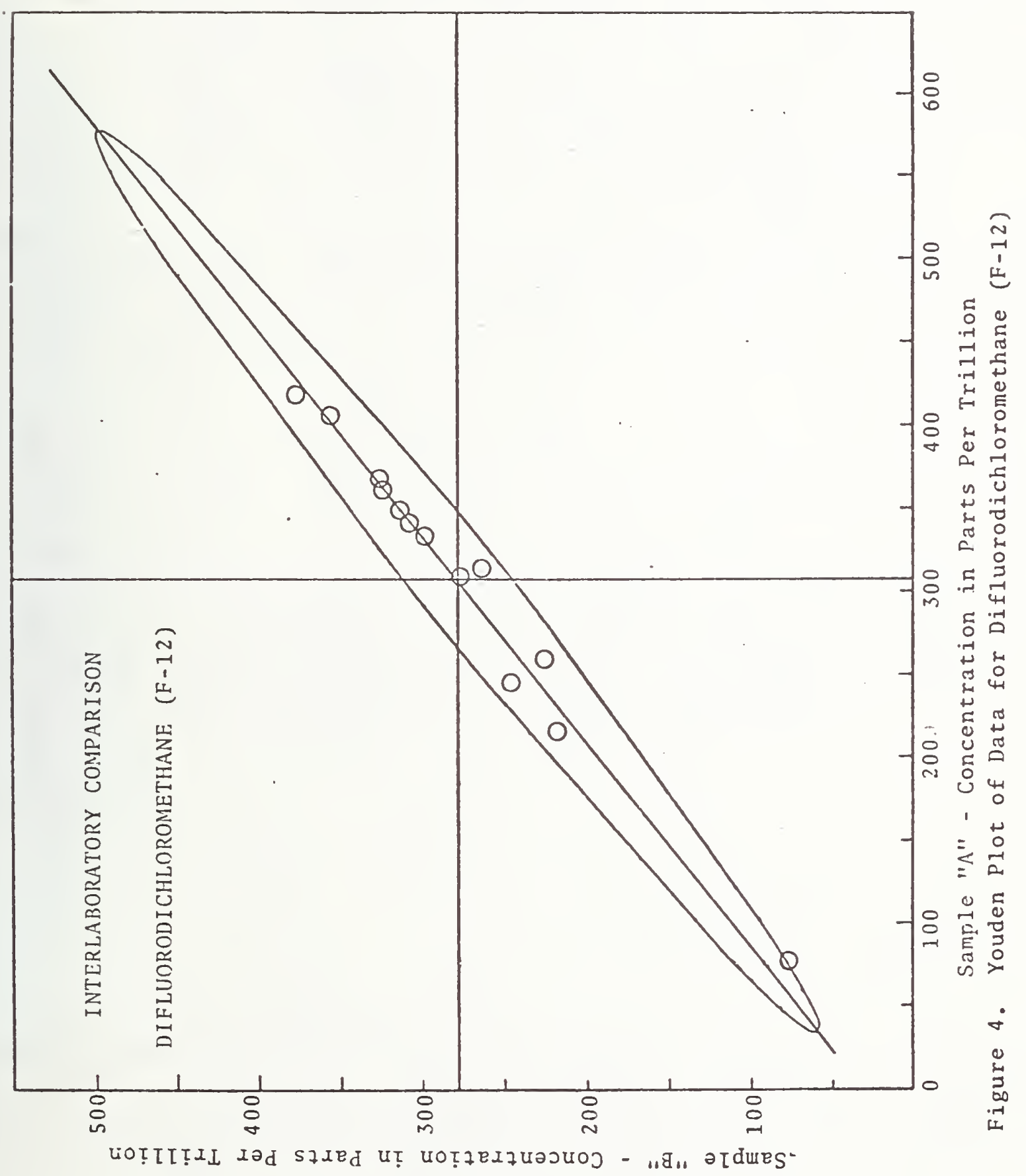


NBS-II4A IREV. $7-70$

\begin{tabular}{|c|c|c|}
\hline $\begin{array}{l}\text { U.S. DEPT. OF COMM. } \\
\text { BIBLIOGRAPHIC DATA } \\
\text { SHEET }\end{array}$ & $\begin{array}{l}\text { 1. PUBLICATION OR REPORT NO. } \\
\text { NBSIR } 78-1480\end{array}$ & 3. Recipient's Accession No. \\
\hline \multicolumn{2}{|l|}{ 4. TIT.LE AND SUBTITLE } & 5. Publication Date \\
\hline \multicolumn{3}{|c|}{$\begin{array}{l}\text { Evaluation of Methodology for Analysis of Halocarbons } \\
\text { in the Upper Atmosphere: Phase I }\end{array}$} \\
\hline \multicolumn{2}{|c|}{$\begin{array}{l}\text { 7. AUTHOR(S) } \\
\text { Ernest E. Hughes, William D. Dorko \& John K. Taylor }\end{array}$} & 8. Performing Organ. Report No. \\
\hline \multicolumn{2}{|c|}{$\begin{array}{l}\text { 9. PERFORMING ORGANIZATION NAME AND ADDRESS } \\
\text { NATIONAL BUREAU OF STANDARDS } \\
\text { DEPARTMENT OF COMMERCE } \\
\text { WASHINGTON, D.C. } 20234\end{array}$} & 10. Project/Task/Work Unit No. \\
\hline \multirow{2}{*}{\multicolumn{2}{|c|}{$\begin{array}{l}\text { 12. Sponsoring Organization Name and Complete Address (Street, City, State, ZIP) } \\
\text { National Atmospheric and Space Administration } \\
\text { Washington, D. C. } 20546\end{array}$}} & $\begin{array}{l}\text { 13. Type of Report \& Period } \\
\text { Covered }\end{array}$ \\
\hline & & 14. Sponsoring Agency Code \\
\hline
\end{tabular}

15. SUPPLEMENTARY NOTES

16. ABSTRACT (A 200-word or less factual summary of most significant information. If document includes a significant bibliography or literature survey, mention it here.)

This report describes the results of Phase I of a collaborative test to evaluate the state-of-the-art of measurement of the concentrations of halocarbons and nitrous oxide in the upper atmosphere. A pair of test samples, differing only slightly in concentration was sent to each of sixteen laboratories. Statistical analysis of the results reported by each laboratory indicates systematic differences between laboratories which are significantly larger than within laboratory precision.

17. KEY WORDS (six to twelve entries; alphabetical order; capitalize only the first letter of the first key word unless a proper name; separated by semicolons)

Air Pollution, Atmospheric Freons, Halocarbon Analysis, Nitrous Oxide, Ozone layer, Trace Gas Analysis
18. AVAILABILITY

$$
[x \text { Unlimited }
$$

For Official Distribution. Do Not Release to NTIS

Order From Sup. of Doc., U.S. Government Printing Office

Washington, D.C. 20402, SD Cat. No. CI3

Order From National Technical Information Service (NTIS)

Springfield, Virginia 22151

\begin{tabular}{|l|c|}
\hline $\begin{array}{l}\text { 19. SECURITY CLASS } \\
\text { (THIS REPURT) }\end{array}$ & 21. NO. OF PAGES \\
UNCL ASSIFIED & 37 \\
\hline $\begin{array}{l}\text { 20. SECURITY CLASS } \\
\text { (THIS PAGE) }\end{array}$ & 22. Price \\
UNCLASSIFIED & $\$ 4.50$ \\
\hline
\end{tabular}

